University of Nebraska - Lincoln

DigitalCommons@University of Nebraska - Lincoln

Faculty Papers and Publications in Animal

Science

Animal Science Department

May 2000

\title{
Parameter estimates for direct and maternal genetic effects on yearling, eighteen-month, and slaughter weights of Korean native cattle
}

J. W. Lee

University of Nebraska-Lincoln

S. B. Choi

National Livestock Research Institute, RDA, Cheonan, 330-800, Korea

Y. H. Jung

National Livestock Research Institute, RDA, Cheonan, 330-800, Korea

Jeffrey F. Keown

University of Nebraska-Lincoln, jkeown1@unl.edu

L. Dale Van Vleck

University of Nebraska-Lincoln, dvan-vleck1@unl.edu

Follow this and additional works at: https://digitalcommons.unl.edu/animalscifacpub

Part of the Animal Sciences Commons

Lee, J. W.; Choi, S. B.; Jung, Y. H.; Keown, Jeffrey F.; and Van Vleck, L. Dale, "Parameter estimates for direct and maternal genetic effects on yearling, eighteen-month, and slaughter weights of Korean native cattle" (2000). Faculty Papers and Publications in Animal Science. 217.

https://digitalcommons.unl.edu/animalscifacpub/217

This Article is brought to you for free and open access by the Animal Science Department at DigitalCommons@University of Nebraska - Lincoln. It has been accepted for inclusion in Faculty Papers and Publications in Animal Science by an authorized administrator of DigitalCommons@University of Nebraska - Lincoln. 


\title{
Parameter estimates for direct and maternal genetic effects on yearling, eighteen-month, and slaughter weights of Korean native cattle ${ }^{1}$
}

\author{
J. W. Lee*, S. B. Choi $\dagger$, Y. H. Jung $\dagger$, J. F. Keown ${ }^{*, 2}$, and L. D. Van Vleck \\ *Department of Animal Science, University of Nebraska, Lincoln 68583-0908; †Livestock Improvement \\ Department, National Livestock Research Institute, RDA, Cheonan, 330-800, Korea; \\ and $\ddagger$ USDA, ARS, Roman L. Hruska U.S. Meat Animal Research Center, Lincoln, NE 68583-0908
}

\begin{abstract}
Data collected by the National Livestock Research Institute of the Rural Development Administration of Korea were used to estimate genetic parameters for yearling (YWT, $\mathrm{n}=5,848$ ), 18-mo (W18, $\mathrm{n}=4,585$ ), and slaughter (SWT, $\mathrm{n}=2,279$ ) weights for Korean Native cattle. Nine animal models were used to obtain REML estimates of genetic parameters: DP2 included genetic, uncorrelated dam, and residual random effects; DQ-2 included genetic, sire $\times$ region $\times$ yearseason interaction, and residual random effects; DPQ2 was based on DQ-2 but included both interaction and dam effects; DMP-2 was based on DP-2 but with dam effect partitioned to include maternal genetic and permanent environmental effects; and DMPQ-2 was based on DMP-2 but also included sire interaction effects. Those five models included two fixed factors: region $x$ year-season and age of dam $\times$ sex effects. Models DP3, DQ-3, DPQ-3, and DMPQ-3 were based on DP-2, DQ2, DPQ-2, and DMPQ-2 but included as a third fixed factor whether or not identification of the sire was known. Estimates of heritability with DMPQ-3 for YWT, with DPQ-3 for W18 and SWT when analyzed with single-trait analyses were $.14, .11$, and .17 , respectively, and were nearly the same with bivariate analy-
\end{abstract}

ses. Estimate of maternal heritability for YWT from single-trait analysis was .04, with estimates for other traits near zero. For bivariate analyses, the estimate for YWT was .01. With single trait analysis, estimate of the direct-maternal genetic correlation for YWT was negative (-.81). Estimates of direct genetic correlations between YWT and W18, YWT and SWT, and W18 and SWT were .99, 1.00, and .97, respectively. Estimates of environmental correlations varied from .60 to .81; the largest was between W18 and SWT. Including a fixed factor for whether sire identification was missing or not missing reduced the estimate of heritability for slaughter weight. The results suggest that the sire $\times$ region $x$ year-season interaction is important for yearling weight and may be needed in a model for slaughter weight. Maternal effects may be of slight importance for yearling weight but of no importance for W18 and SWT. Models for national cattle evaluations for Korean Native cattle for YWT should be considered that include maternal genetic and permanent environmental as well as sire $\times$ region $\times$ year-season interaction effects, but those effects seem not to be needed for models for W18 and SWT. Not much reranking of sires occurred when ranked was based on the different models for W18 and SWT.

Key Words: Beef Cattle, Genetic Parameters, Growth

(C2000 American Society of Animal Science. All rights reserved.

J. Anim. Sci. 2000. 78:1414-1421

\section{Introduction}

Maternal effects on postweaning growth traits of beef cattle have been found in some breeds (Koch et al., 1973; Alenda et al., 1980; Meyer, 1992). Lee et al. (1991) reported estimates of heritability of .19 for yearling

\footnotetext{
${ }^{1}$ Published as paper no. 12582, Journal Ser., Nebraska Agric. Res. Div., Univ. of Nebraska, Lincoln 68583-0908.

${ }^{2}$ Correspondence: A218 Animal Sciences, University of Nebraska, Lincoln 68583-0908 (phone: 402-472-6453; fax: 402-472-6362; Email: jkeown@unl.edu).

Received May 7, 1999.

Accepted December 6, 1999.
}

weight and of .04 for 18-mo weight in Korean Native cattle. Numerous studies have also reported nonzero estimates of genetic correlation between direct and maternal genetic effects on yearling weight; for example, -.39 and .01 for Zebu crosses, -.48 for Herefords, and .49 for Angus in Australia (Meyer, 1992; Mackinnon et al., 1991). Diop (1997) reported negative genetic correlations between direct and maternal genetic effects for yearling and 18-mo weights of Gobra cattle in Senegal to be -.50 and -.28 , respectively.

Including effects of sire $\times$ herd $\times$ year interaction (Dodenhoff et al., 1998) and of sire $\times$ year interaction (Lee and Pollak, 1997; Robinson, 1994) in models for genetic evaluation of beef cattle has been investigated. 
Table 1. Summary of observations, overall means, and standard deviations (SD) ${ }^{\text {a }}$ by trait

\begin{tabular}{lrrr}
\hline \hline & \multicolumn{3}{c}{ Trait $^{\mathrm{b}}$} \\
\cline { 2 - 4 } & YWT & W18 & SWT \\
\hline Mean, kg & 290 & 434 & 534 \\
SD, kg & 66 & 84 & 80 \\
Number & & & \\
Records & 5,848 & 4,585 & 2,279 \\
Sires & 1,426 & 1,077 & 292 \\
Assigned sires & 52 & 31 & 4 \\
Dams & 4,085 & 3,238 & 1,705 \\
Assigned dams & 1,130 & 879 & 557 \\
SRYS & 1,625 & 1,170 & 353 \\
\hline
\end{tabular}

${ }^{a}$ Records unadjusted for model effects

${ }^{\text {b}}$ YWT = yearling weight, W18 = 18-mo weight, and SWT = slaughter weight.

'SRYS $=$ sire $\times$ region $\times$ year-season combinations.

Lee and Pollak (1997) and Robinson (1994) reported that the negative direct-maternal genetic correlation was inflated when the effects of sire $\times$ year interaction were not included in the model. Dodenhoff et al. (1998) suggested that including sire $\times$ herd-year interaction effects in models for genetic evaluation might result in considerable reranking for estimated breeding values for maternal weaning weight.

The objective of this study was to estimate genetic parameters associated with direct and maternal genetic effects on yearling, 18-mo, and slaughter weights of Korean Native cattle. Impacts on genetic parameters resulting from including sire $\times$ region $\times$ year-season interaction effects in the analytical models for yearling, 18-mo, and slaughter weights were also evaluated. These parameters are needed to develop genetic evaluation programs for Korean Native cattle.

\section{Materials and Methods}

Data were collected from 1974 through 1995 by the National Livestock Research Institute (NLRI) in Rural Development Administration (RDA) of Korea. Numbers of records, overall means, and standard deviations by trait are in Table 1. Total number of animals in pedigrees was 20,999.

Most cows suckled calves for 3 to 4 mo. At about 3 wk of age, calves are provided prestarter. Weaning weight was recorded at about 4 mo (120 d). Weaned calves may have been placed in drylot or pasture (or both) and were generally castrated at about 5 mo of age. From 4 mo to 6 mo of age, it was recommended that calves be provided concentrates (CP 18\%, TDN $70 \%$ ) and grazing forage. From 6 mo to 13 mo, calves were generally provided concentrates (CP 15 to $16 \%$, TDN 60 to 70\%) and grazing forage. From 13 mo to 24 mo, steers were generally provided concentrates (CP 11 to $13 \%$, TDN 71 to $73 \%$ ) and grazing forage.

The adjusted measure of yearling weight (365-d) in this study provided by NLRI-RDA was
Adjusted 365-d weight, kg

$=\frac{\text { actual yearling weight }- \text { actual weaning weight }}{\text { No. of days from weaning to yearling }}$

$\times 245+$ actual weaning weight

Adjusted 18-mo weight (550-d) was

Adjusted 550-d weight, kg

$=\frac{\text { actual } 18 \text {-mo weight }- \text { actual weaning weight }}{\text { No. of days from weaning to } 18 \mathrm{mo}}$

$\times 430+$ actual weaning weight

These adjustments require the assumption of linear growth over long intervals. However, the adjusted weights are the data available from NLRI-RDA at the present time.

Weights were obtained at slaughter with average age at slaughter of 22 mo. Estimates of variance components for actual slaughter weight were similar whether or not slaughter age was included as a covariate.

Nine single-trait animal models were initially used to determine appropriate models for multiple-trait analyses. Region $\times$ year-season and age of dam $\times$ sex were fit as fixed effects in all models. For all models, year-season was defined with a spring season and a fall season. Two recording regions were involved. Age of dam was classified by years and ranged from 2 to 16 yr. Herd identification was not available from NLRI.

Analyses for single traits were based on the following models. Model DP-2 included direct genetic, uncorrelated dam, and residual environmental random effects with

$$
\mathbf{y}=\mathrm{X} \boldsymbol{\beta}+\mathrm{Z}_{1} \mathbf{a}+\mathrm{W}_{1} \mathbf{p}+\mathbf{e}
$$

where $\mathbf{y}$ is a $\mathrm{N} \times 1$ vector of observations; $\boldsymbol{\beta}$ is vector of fixed effects (region $\times$ year-season combinations and age of dam $\times$ sex combinations); $\mathbf{a}$ is vector of direct genetic effects; $\mathbf{p}$ is vector of uncorrelated dam effects; $\mathbf{e}$ is vector of random residual effects; and $\mathrm{X}, \mathrm{Z}_{1}$, and $\mathrm{W}_{1}$ are known matrices relating observations in $y$ to fixed and random effects.

Model DQ-2 included direct genetic, sire $\times$ region $\times$ year-season (SRYS) interaction, and residual environmental random effects:

$$
\mathbf{y}=\mathrm{X} \boldsymbol{\beta}+\mathrm{Z}_{1} \mathbf{a}+\mathrm{W}_{2} \mathbf{q}+\mathbf{e}
$$

where $\mathbf{q}$ is vector of sire $\times$ region $\times$ year-season interaction effects and $\mathrm{W}_{2}$ is a known matrix relating observations in $\mathbf{y}$ to random effects in $\mathbf{q}$.

Model DPQ-2 was based on DQ-2 but was extended to include an uncorrelated dam effect $(p)$ :

$$
\mathbf{y}=\mathrm{X} \boldsymbol{\beta}+\mathrm{Z}_{1} \mathbf{a}+\mathrm{W}_{1} \mathbf{p}+\mathrm{W}_{2} \mathbf{q}+\mathbf{e}
$$


Table 2. Parameters estimated with the nine models

\begin{tabular}{|c|c|c|c|c|c|c|c|}
\hline \multirow[b]{2}{*}{ Model $^{\text {b }}$} & \multicolumn{7}{|c|}{ Parameters $^{\mathrm{a}}$} \\
\hline & $\sigma_{a}^{2}$ & $\sigma_{m}^{2}$ & $\sigma_{a m}$ & $\sigma_{p}^{2}$ & $\sigma_{q}^{2}$ & $\sigma_{e}^{2}$ & Fixed \\
\hline DP-2 & $\checkmark$ & & & $\checkmark$ & & $\checkmark$ & 2 \\
\hline DQ-2 & $\checkmark$ & & & & $\checkmark$ & $\checkmark$ & 2 \\
\hline DPQ-2 & $\checkmark$ & & & $\checkmark$ & $\checkmark$ & $\checkmark$ & 2 \\
\hline DMP-2 & $\checkmark$ & $\checkmark$ & $\checkmark$ & $\checkmark$ & & $\checkmark$ & 2 \\
\hline DMPQ-2 & $\checkmark$ & $\checkmark$ & $\checkmark$ & $\checkmark$ & $\checkmark$ & $\checkmark$ & 2 \\
\hline DP-3 & $\checkmark$ & & & $\checkmark$ & & $\checkmark$ & 3 \\
\hline DQ-3 & $\checkmark$ & & & & $\checkmark$ & $\checkmark$ & 3 \\
\hline DPQ-3 & $\checkmark$ & & & $\checkmark$ & $\checkmark$ & $\checkmark$ & 3 \\
\hline DMPQ-3 & $\checkmark$ & $\checkmark$ & $\checkmark$ & $\checkmark$ & $\checkmark$ & $\checkmark$ & 3 \\
\hline
\end{tabular}

${ }^{\mathrm{a}} \sigma_{a}^{2}=$ direct genetic variance, $\sigma_{m}^{2}=$ maternal genetic variance, $\sigma_{a m}=$ covariance between direct and maternal effects, $\sigma_{p}^{2}=$ variance due to effect of dam (genetic and permanent environmental if maternal genetic effects not in the model, and variance due to maternal permanent environmental effects if maternal genetic effects in the model), $\sigma_{q}^{2}=$ variance of sire $\times$ region $\times$ year-season interaction effects, $\sigma_{e}^{2}=$ variance of temporary environmental effects, and Fixed $=$ fixed factors in the model $(2=$ region $\times$ year-season and age of dam $\times$ sex effects; $3=$ region $\times$ year-season effects, age of dam $\times$ sex effects, and whether sire identification was missing or not).

${ }^{\mathrm{b}} \mathrm{D}=$ direct genetic effects, $\mathrm{M}=$ maternal genetic effects, $\mathrm{P}=$ effect of dam (genetic plus permanent environmental if maternal genetic effects not in the model, and maternal permanent environmental effect if maternal genetic effect in the model), $Q=$ sire $\times$ region $\times$ year-season interaction effects, $2=$ two fixed factors (region $\times$ year-season and age of dam $\times$ sex effects), and $3=$ three fixed factors (region $\times$ year-season effects, age of dam $\times$ sex effects, and whether sire identification was missing or not).

Model DMP-2 was based on DP-2 but was extended to partition the dam effect into maternal genetic and permanent environmental effects:

$$
\mathbf{y}=\mathrm{X} \boldsymbol{\beta}+\mathrm{Z}_{1} \mathbf{a}+\mathrm{Z}_{2} \mathbf{m}+\mathrm{W}_{1} \mathbf{p}+\mathbf{e}
$$

where, in contrast to DP-2, the vector of dam effects was partitioned into $\mathbf{m}$, a vector of correlated maternal genetic effects, and $\mathbf{p}$, a vector of uncorrelated maternal permanent environmental effects, with $\mathrm{X}, \mathrm{Z}_{1}, \mathrm{Z}_{2}$, and $\mathrm{W}_{1}$ known matrices relating observations in $\mathbf{y}$ to fixed and random effects.

Model DMPQ-2 was based on DMP-2 but was extended to include a random sire $\times$ region $\times$ year-season (SRYS) interaction effect:

$$
\mathbf{y}=\mathrm{X} \boldsymbol{\beta}+\mathrm{Z}_{1} \mathbf{a}+\mathrm{Z}_{2} \mathbf{m}+\mathrm{W}_{1} \mathbf{p}+\mathrm{W}_{2} \mathbf{q}+\mathbf{e}
$$

Models DP-3, DQ-3, DPQ-3, and DMPQ-3 were based on DP-2, DQ-2, DPQ-2, and DMPQ-2, respectively, but included as a third fixed factor, whether or not identification of the sire was missing, with unique dummy sire identification numbers assigned if identification of a sire was missing for a record. The missing or nonmissing sires were nested within the corresponding missing sire factor (denoted in the data set as 1 for a missing sire and as 2 for known sire identification).

The nine single-trait animal models are summarized in Table 2.

For all models, $\mathrm{E}[\mathrm{y}]=\mathrm{X} \boldsymbol{\beta}$ and the (co)variance structure of the random effects for the most complete models, DMPQ-2 and DMPQ-3, was

$$
\mathrm{V}\left[\begin{array}{l}
\mathrm{a} \\
\mathrm{m} \\
\mathrm{p} \\
\mathrm{q} \\
\mathrm{e}
\end{array}\right]=\left[\begin{array}{ccccc}
\mathrm{A} \sigma_{\mathrm{a}}^{2} & \mathrm{~A} \sigma_{\mathrm{am}} & 0 & 0 & 0 \\
\mathrm{~A} \sigma_{\mathrm{am}} & \mathrm{A} \sigma_{\mathrm{m}}^{2} & 0 & 0 & 0 \\
0 & 0 & \mathrm{I}_{\mathrm{N}_{\mathrm{d}}} \sigma_{\mathrm{p}}^{2} & 0 & 0 \\
0 & 0 & 0 & \mathrm{I}_{\mathrm{N}_{\mathrm{s}}} \sigma_{\mathrm{q}}^{2} & 0 \\
0 & 0 & 0 & 0 & \mathrm{I}_{\mathrm{N}} \sigma_{\mathrm{e}}^{2}
\end{array}\right]
$$

where $\mathrm{N}_{\mathrm{d}}=$ number of dams, $\mathrm{N}_{\mathrm{s}}=$ number of sire $\times$ region $\times$ year-season combinations, $\mathrm{N}=$ number of records, $\mathrm{A}$ $=$ numerator relationship matrix among animals in the pedigree file, and I = identity matrix of appropriate order. Other models had a subset of this (co)variance structure.

Estimates of genetic parameters were obtained with MTDFREML (Boldman et al., 1995), a set of programs for estimating (co)variance components using animal models and derivative-free REML (Smith and Graser, 1986; Graser et al., 1987). The program was restarted with the estimates at previous apparent convergence as initial values until a global minimum of -2 of the log likelihood was found (i.e., when -2 log of the likelihood did not change to the third decimal after consecutive restarts).

Fitting sire $\times$ region $\times$ year-season and maternal genetic effects required each animal with a record to have a sire and a dam. Therefore, unique "assigned" sire and dam identification was given to records if sires and(or) dams were unknown. The numbers of observations with assigned sires and dams are given in Table 1.

\section{Results and Discussion}

Direct and maternal genetic effects and their covariance were previously established as important for birth, 
weaning (4-mo), and 6-mo weights of Korean Native cattle (Choi et al., 2000). For example, heritability estimates for weaning weight were .13 and .07 for direct and maternal effects, respectively, with genetic correlations between these effects of -.44 in a model without sire $\times$ region $\times$ year-season interaction effects. Estimates for a model with sire $\times$ region $\times$ year-season interaction effects were $.03, .05$, and .11 , respectively.

\section{Yearling Weight}

Parameter estimates for yearling weight with the nine models are shown in Table 3 for single-trait analyses. Estimates of direct heritability for yearling weight ranged from .10 to .23 and averaged .14 across all models. The small estimates of heritability may indicate the possibility of misidentification of sires. Lee and Pollak (1997) showed using simulation that misidentification of sires can substantially reduce estimates of heritability and produced spurious sire $\times$ year interaction effects.

Models that included maternal genetic effects for yearling weight resulted in significantly better log likelihoods than models that ignored maternal genetic effects. Estimates of variance due to direct genetic effects were increased for DMP-2 vs DP-2 and DMPQ-2 vs DPQ-2. Estimates of maternal heritability were smaller than direct heritability for the three models with maternal genetic effects. Including maternal genetic effects in the model may have partitioned total genetic variance differently. The sum of genetic (co)variances for DMP2 was 260 compared with total genetic variance for DP-
2 of 246. Similarly, the total genetic variance for DMPQ-2 was 164 compared with 153 for DP-2. The stability of total genetic variance probably reflects large sampling covariances among estimates of its components. Estimates of direct-maternal genetic correlation for those three models were negative and large (-.80 to -.91 ). The signs of these estimates of the direct-maternal correlation agree with Meyer (1992), who reported an estimate of -.48 in Australian Hereford cattle and Diop (1997) who reported an estimate of -.50 in Gobra cattle of Senegal.

Very few animals had missing sire identification. However, including whether sire identification was missing as a fixed factor in the model resulted in an improvement in the log likelihood, although estimates of variance components for DMPQ-3 were similar to those for DMPQ-2.

Including sire $\times$ region $\times$ year-season interaction effects in the model improved the fit of the model and affected estimates of the variances (Table 3). Direct heritability was reduced with DPQ-2 vs DP-2, DMPQ2 vs DMP-2, and with DP-3 vs DPQ-3. The reduced estimates of heritability that resulted from including the sire $\times$ region $\times$ year-season interaction in the model indicate that these interaction effects may be representing herd effects. To the degree that genetic effects and herd effects were confounded, inflated estimates of heritability may result from not partitioning these effects correctly. Genetic correlation between direct and maternal genetic effects was -.80 for DMPQ-2 which included sire $\times$ region $\times$ year-season interaction effects,

Table 3. Estimates of variance components and genetic parameters (standard errors) for yearling weight (kg)

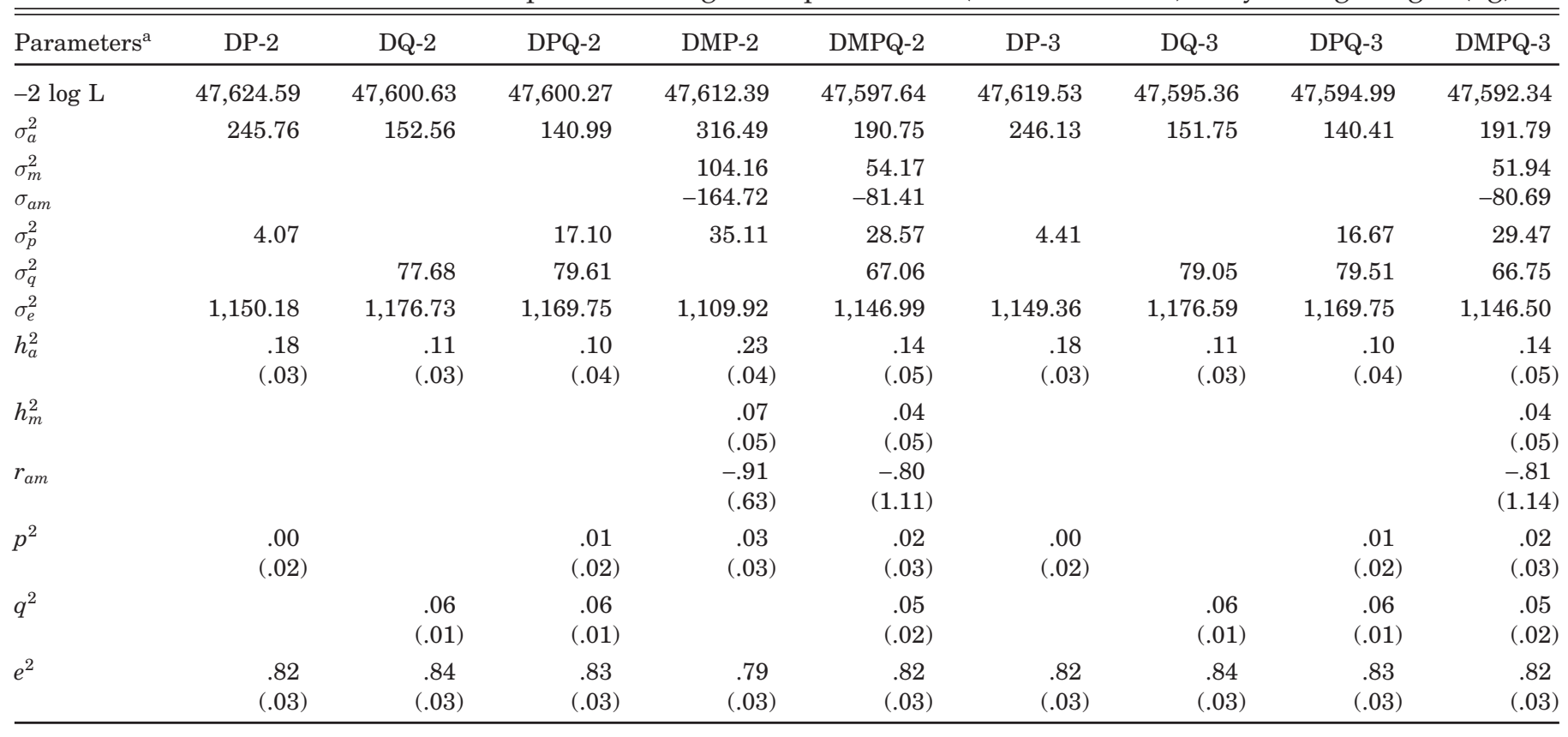

\footnotetext{
${ }^{\mathrm{a}} \sigma_{a}^{2}=$ direct genetic variance, $\sigma_{m}^{2}=$ maternal genetic variance, $\sigma_{a m}=$ covariance between direct and maternal effects, $\sigma_{p}^{2}=$ variance of maternal permanent environmental effects, $\sigma_{q}^{2}=$ variance of sire $\times$ region $\times$ year-season interaction effects, $\sigma_{e}^{2}=$ variance of temporary environmental effects, $h_{a}^{2}=$ direct heritability, $h_{m}^{2}=$ maternal heritability, $r_{a m}=$ genetic correlation between direct and maternal effects, $p^{2}=$ fraction of variance due to maternal permanent environmental effects, $q^{2}=$ fraction of variance due to sire $\times$ region $\times$ year-season interaction effects, and $e^{2}=$ fraction of variance due to residual effects.
} 
Table 4. Estimates of variance components and genetic parameters (standard errors) for 18-mo weight (kg)

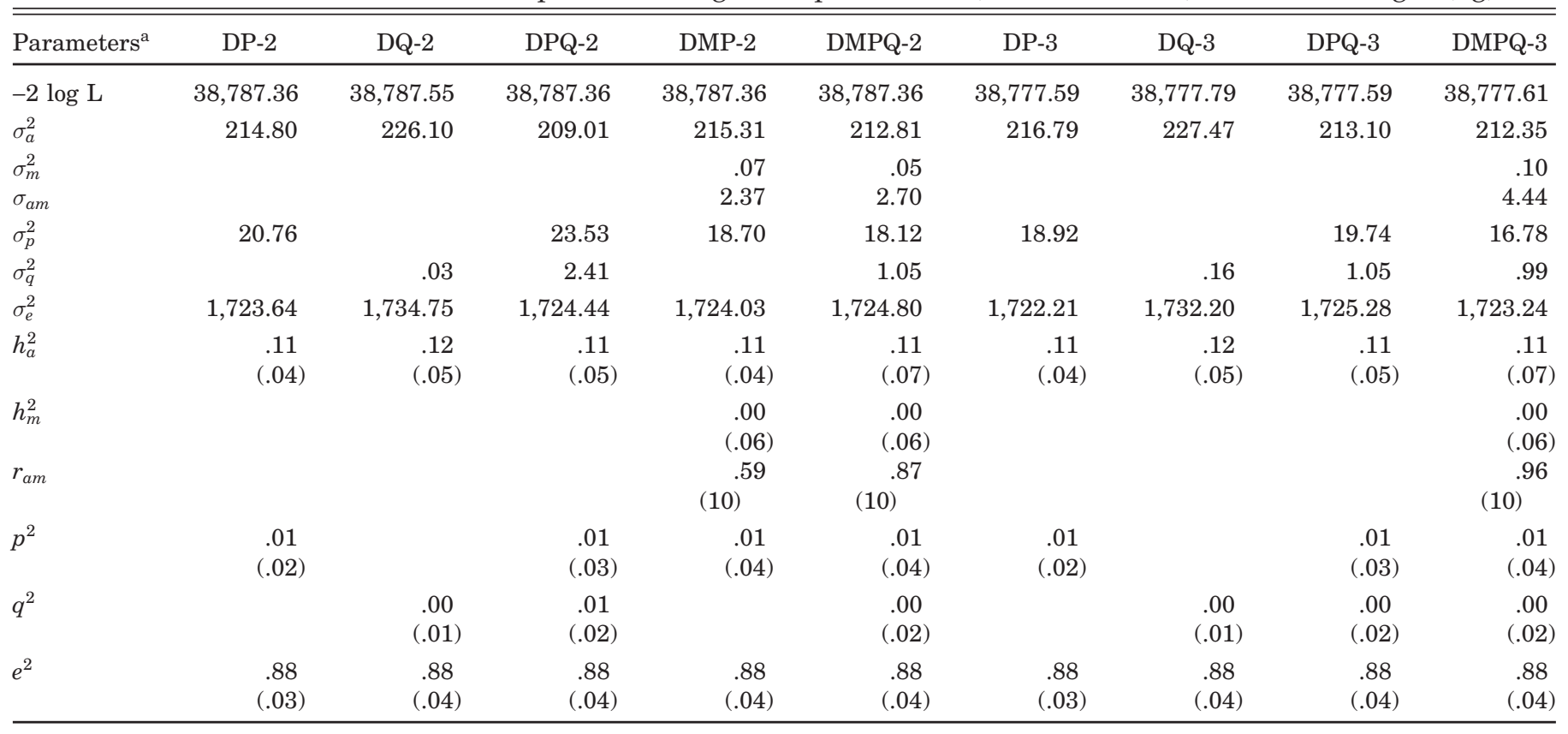

${ }^{\mathrm{a}} \sigma_{a}^{2}=$ direct genetic variance, $\sigma_{m}^{2}=$ maternal genetic variance, $\sigma_{a m}=$ covariance between direct and maternal effects, $\sigma_{p}^{2}=$ variance of maternal permanent environmental effects, $\sigma_{q}^{2}=$ variance of sire $\times$ region $\times$ year-season interaction effects, $\sigma_{e}^{2}=$ variance of temporary environmental effects, $h_{a}^{2}=$ direct heritability, $h_{m}^{2}=$ maternal heritability, $r_{a m}=$ genetic correlation between direct and maternal effects, $p^{2}=$ fraction of variance due to maternal permanent environmental effects, $q^{2}=$ fraction of variance due to sire $\times$ region $\times$ year-season interaction effects, and $e^{2}=$ fraction of variance due to residual effects.

and was -.91 for DMP-2 which ignored sire $\times$ region $\times$ year-season interaction effects. These results agreed with those of Lee and Pollak (1997) who suggested negative estimates of direct-maternal genetic correlations for weaning weight were inflated when the effects of sire $\times$ year interaction were not included in the model. A reason for why the estimate is so large and negative is not apparent although one reason may be that the pedigree structure might not be adequate for obtaining estimates of both direct and maternal heritabilities and the direct-maternal genetic correlation.

\section{Eighteen-Month Weight}

Estimates of genetic parameters from single-trait analyses for 18-mo weight from the nine models are reported in Table 4. Maternal effects do not seem important for 18-mo weight. Variance components for maternal genetic effects for DMP-2, DMPQ-2, and DMPQ3 were less than $1 \%$ of phenotypic variance. However, there may be need to include a general effect of dam in the model because including that effect seemed to reduce slightly the estimate of direct heritability. These results differ from Diop (1997), who reported maternal genetic effects accounted for a significant proportion of total variance for 18-mo (final) weight in Gobra beef cattle of Senegal. Estimates of direct heritability for 18-mo weight were similar with all models, ranging from .11 to .12. Similarly, Diop (1997) reported an estimate of direct heritability for final (18-mo) weight of .13. These estimates seem low compared with estimates for mature weight and may be due to misidentification even though the estimated variance due to sire $\times$ region $\times$ year-season interaction was small. No other literature was found reporting analyses of 18 -mo weight, although Kersey DeNise and Ray (1987) reported an estimate of direct heritability for 20-mo weight of . 29 for Herefords.

Estimates of variance due to effects of sire $\times$ region $\times$ year-season interaction were also small in contrast to the estimates for YWT. This result suggests that the interaction term may not be a surrogate for contemporary group effects for 18-mo weight or that contemporary group effects are not needed to account for management conditions in Korea.

Including the effect of whether sire identification was known or not known improved the fit of the models for 18-mo weight. However, the pattern for estimates of variance components was similar whether or not the effect for missing vs not missing sire identification was present in the model.

\section{Slaughter Weight}

Parameter estimates for slaughter weight from the same models as for 18-mo weight are presented in Table 5. Similar patterns for estimates of variance components were not found for slaughter weight (at average of $22 \mathrm{mo}$ ) as for 18-mo weight. There was more variability from model to model, which might be due to having only about half as much data or may be due to different management conditions and identification standards for animals that were slaughtered. The slaughter 
weights were only on steers, whereas 18 -mo weights included both heifers and steers. Estimates of heritability were larger for slaughter weight than for 18-mo weight, which suggests better identification for slaughtered animals (steers) than animals not slaughtered (heifers). There were only minor differences in the likelihoods for models with the same fixed factors. The log likelihoods with DP-3, DQ-3, and DPQ-3, including the additional fixed factor for missing sire identification, were somewhat improved compared with DP-2, DQ-2, and DPQ-2. Model DPQ-3 for slaughter weight was compared with and without age at slaughter as a covariate and similar log likelihoods were found for both models. Thus, estimates from the model with slaughter age as covariate were not reported. Log likelihoods were essentially the same for models that did or did not include maternal genetic effects, which indicates that maternal effects are not important for slaughter weight as was also concluded for 18-mo weight.

An explanation is lacking for why, with some models, estimates of variance due to sire $\times$ region $\times$ year-season interaction effects were small and had no effect on estimates of heritability but, with other models, estimates of heritability decreased substantially with sire interaction in the model especially with the extra fixed factor. The estimates of the direct-maternal genetic correlation can have little meaning with such small estimates of the maternal genetic variance for slaughter weight.

\section{Multiple-Trait Analyses}

For bivariate analyses, the DMPQ-3 model was first used for yearling weight, which included random direct and maternal genetic, maternal permanent environmental, sire $\times$ region $\times$ year-season interaction, and residual environmental effects and with whether identification of sire was missing or not as an additional fixed factor. Estimated maternal heritability for yearling weight was reduced compared with the estimates from single-trait analyses (.01 vs .04, respectively). Thus, maternal genetic effects were ignored in all subsequent bivariate analyses. For 18-mo weight and slaughter weight, model DPQ-3, which included random direct genetic, uncorrelated dam, sire $\times$ region $\times$ year-season (SRYS) interaction, and residual environmental effects with a fixed factor of whether identification of sire was missing or not, had the best fit. Therefore, this model was used for the three pairs of twotrait analyses.

Parameter estimates from the two-trait analyses for yearling, 18-mo, and slaughter weights are shown in Table 6. Estimates of heritability for yearling weight were somewhat smaller than those from single-trait analyses. Estimates of direct genetic correlations between YWT and W18, YWT and SWT, and W18 and SWT were large: .99, 1.00, and .97, respectively. Koots et al. (1994) reported average estimates of direct genetic correlations between yearling weight and postweaning

Table 5. Estimates of variance components and genetic parameters (standard errors) for slaughter weight $(\mathrm{kg})$

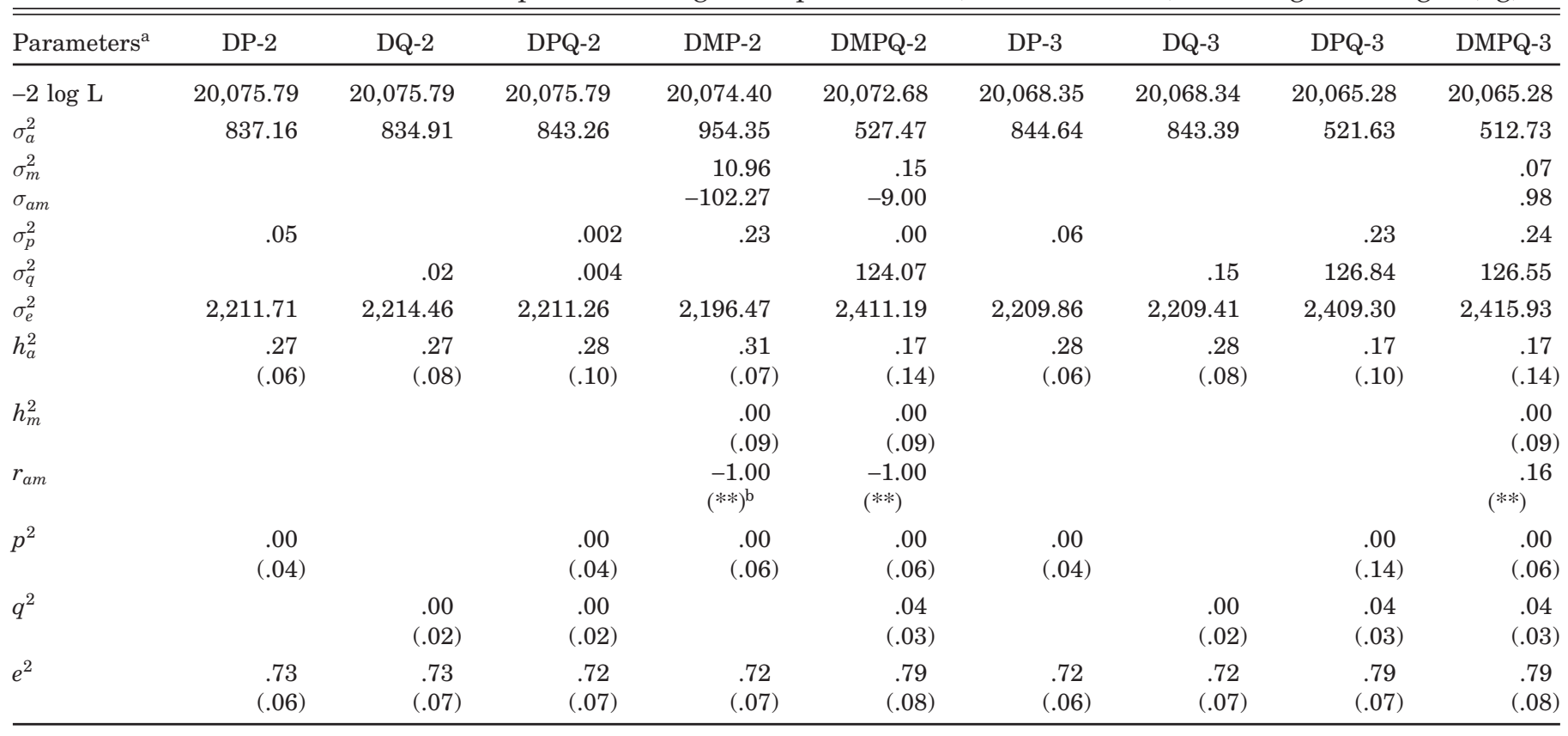

\footnotetext{
${ }^{\mathrm{a}} \sigma_{a}^{2}=$ direct genetic variance, $\sigma_{m}^{2}=$ maternal genetic variance, $\sigma_{a m}=$ covariance between direct and maternal effects, $\sigma_{p}^{2}=$ variance of maternal permanent environmental effects, $\sigma_{q}^{2}=$ variance of sire $\times$ region $\times$ year-season interaction effects, $\sigma_{e}^{2}=$ variance of temporary environmental effects, $h_{a}^{2}=$ direct heritability, $h_{m}^{2}=$ maternal heritability, $r_{a m}=$ genetic correlation between direct and maternal effects, $p^{2}=$ fraction of variance due to maternal permanent environmental effects, $q^{2}=$ fraction of variance due to sire $\times$ region $\times$ year-season interaction effects, and $e^{2}=$ fraction of variance due to residual effects.

${ }^{\mathrm{b}}$ Not estimable.
} 
Table 6. Parameter estimates from two-trait analyses for yearling and 18-mo weights, yearling and slaughter weights, and 18-mo and slaughter weights $(\mathrm{kg})$

\begin{tabular}{|c|c|c|c|c|c|c|c|c|c|c|c|c|c|}
\hline \multicolumn{2}{|c|}{ Trait $^{\mathrm{a}}$} & \multirow[b]{2}{*}{$\sigma_{y_{1}}^{2}$} & \multirow[b]{2}{*}{$\sigma_{y_{2}}^{2}$} & \multirow[b]{2}{*}{$h_{a_{1}}^{2}$} & \multirow[b]{2}{*}{$h_{a_{2}}^{2}$} & \multirow[b]{2}{*}{$r_{a_{1} a_{2}}$} & \multirow[b]{2}{*}{$p_{1}^{2}$} & \multirow[b]{2}{*}{$p_{2}^{2}$} & \multirow[b]{2}{*}{$q_{1}^{2}$} & \multirow[b]{2}{*}{$q_{2}^{2}$} & \multirow[b]{2}{*}{$r_{p_{1} p_{2}}$} & \multirow[b]{2}{*}{$r_{q_{1} q_{2}}$} & \multirow[b]{2}{*}{$r_{e_{1} e_{1}}$} \\
\hline 1 & 2 & & & & & & & & & & & & \\
\hline YWT & W18 & $1,412.81$ & $2,281.19$ & .10 & .14 & .99 & .01 & .00 & .06 & .02 & 1.00 & .89 & .74 \\
\hline YWT & SWT & $1,413.19$ & $3,369.19$ & .12 & .16 & 1.00 & .01 & .00 & .06 & .05 & 1.00 & .79 & .60 \\
\hline W18 & SWT & $2,003.43$ & $3,035.23$ & .12 & .16 & .97 & .00 & .00 & .00 & .01 & 1.00 & 1.00 & .81 \\
\hline
\end{tabular}

${ }^{\text {aYWT }}$ = yearling weight, W18 = 18-mo weight, SWT = slaughter weight, $\sigma_{y_{1}}^{2}=$ phenotypic variance for trait $1, \sigma_{y_{2}}^{2}=$ phenotypic variance for trait $2, h_{a_{1}}^{2}=$ heritability for trait $1, h_{a_{2}}^{2}=$ heritability for trait 2 , $r_{a_{1} a_{2}}=$ genetic correlation between direct effects for each trait, $p_{1}^{2}=$ fraction of variance due to maternal (genetic and permanent environmental) effects for trait $1, p_{2}^{2}=$ fraction of variance due to maternal (genetic and permanent environmental) effects for trait $2, q_{1}^{2}=$ fraction of variance due to sire $\times$ region $\times$ year-season interaction effects for trait $1, q_{2}^{2}=$ fraction of variance due to sire $\times$ region $\times$ year-season interaction effects for trait $2, r_{p_{1} p_{2}}=$ genetic correlation between fraction of variance due to maternal permanent environmental effects for traits 1 and 2, $r_{q_{1} q_{2}}=$ genetic correlation between fraction of variance due to sire $\times$ region $\times$ yearseason interaction effects for traits 1 and 2, and $r_{e_{1} e_{2}}=$ correlation between environmental effects for traits 1 and 2 .

gain to be .81 , and between yearling weight and carcass weight to be .91. Koch (1978) reported an estimate of .96 for the genetic correlation between yearling weight and carcass weight in Herefords. Arnold et al. (1991), however, estimated the genetic correlation between 365 -d weight and carcass weight to be -.03 for Hereford steers.

Estimates of the correlation between effects of dams for two-trait analyses were highly positive (1.00) but have little meaning because of the small estimate of variance due to effects of dams for these weights $(.00$ to .01).

The proportion of variance due to SRYS interaction effects for yearling weight were somewhat greater than those from single-trait analyses. The estimates of correlations among SRYS interaction effects were .89 for YWT and W18, .79 for YWT and SWT, and 1.00 for W18 and SWT, respectively. However, the estimate of correlation between W18 and SWT due to SRYS interaction effects (1.00) may be meaningless because of the small proportion of variance due to SRYS interaction effects for 18-mo weight.

Estimates of correlations between environmental effects were .74 for YWT and W18, .60 for YWT and SWT, and .81 for W18 and SWT, respectively.

\section{Ranking of Sires}

A comparison of rankings of sires for estimated breeding value for the eight models compared with the complete model for yearling, 18-mo, and slaughter weights is presented in Table 7. To evaluate the effect of the model, sires were ranked based on the predicted breeding values for each model, and then the means of estimated breeding values with the complete model of the top $20 \%$ sires for each ranking were calculated. Little

Table 7. Comparison of rankings of sires for various models compared with the complete model $\left(^{*}\right)$ for yearling, 18-mo, and slaughter weights

\begin{tabular}{|c|c|c|c|c|c|c|c|c|c|}
\hline \multirow[b]{3}{*}{ Model } & \multicolumn{9}{|c|}{ Traits } \\
\hline & \multicolumn{3}{|c|}{ Yearling weight } & \multicolumn{3}{|c|}{ 18-mo weight } & \multicolumn{3}{|c|}{ Slaughter weight } \\
\hline & No. sires $^{a}$ & Corr'n ${ }^{b}$ & Mean $^{\mathrm{c}}$ & No. sires & Corr'n & Mean & No. sires & Corr'n & Mean \\
\hline DP-2 & 252 & .92 & 5.51 & 210 & .99 & 6.36 & 56 & .99 & 11.82 \\
\hline DQ-2 & 252 & .91 & 5.50 & 210 & .99 & 6.36 & 56 & .99 & 11.82 \\
\hline DPQ-2 & 252 & .92 & 5.50 & 210 & .99 & 6.36 & 56 & .99 & 11.82 \\
\hline DMP-2 & 270 & .98 & 5.73 & 210 & .99 & 6.36 & 55 & .98 & 11.67 \\
\hline DMPQ-2 & 282 & .99 & 5.86 & 210 & .99 & 6.36 & 58 & 1.00 & 12.05 \\
\hline DP-3 & 252 & .92 & 5.51 & 215 & 1.00 & 6.46 & 56 & .99 & 11.82 \\
\hline DQ-3 & 251 & .92 & 5.49 & 214 & .99 & 6.44 & 56 & .99 & 11.82 \\
\hline DPQ-3 & 251 & .92 & 5.49 & 214 & .99 & 6.44 & 58 & 1.00 & 12.05 \\
\hline DMPQ-3 & 285 & $*$ & 5.89 & 215 & $*$ & 6.46 & 58 & $*$ & 12.05 \\
\hline
\end{tabular}

${ }^{a}$ Number of sires selected (top 20\%) with this model that were the same as the top $20 \%$ of sires selected with the complete model.

${ }^{b}$ Product moment correlation coefficient between estimated breeding values with this and the full model.

${ }^{\mathrm{c}}$ Mean of estimated breeding values from the full model for the top $20 \%$ selected with this model. 
reranking of sires occurred when compared with the complete model for each trait. Models without maternal genetic effects were most different from the complete model for yearling weight with a product-moment correlation of about .92, and up to 33/285 dropped out of the top $20 \%$. The results indicate that genetic progress would be similar for 18-mo weight and slaughter weight if selection of sires were by any of the models.

\section{Implications}

Maternal effects may not be needed in models for genetic evaluations for postweaning growth performance traits of 18-mo and slaughter weights of Korean Native cattle, but they may be of some importance for yearling weight. Including sire $\times$ region $\times$ year-season interaction effects in the model reduced estimates of heritability for yearling weight, which indicates that sire $\times$ region $\times$ year-season effects may represent contemporary group or herd effects, which, if confounded with genetic effects, would inflate estimates of heritability for yearling weight. Thus, recording herd identification should be encouraged in order to improve genetic evaluation. Estimates of direct genetic correlations among yearling, 18-mo, and slaughter weights were large enough that there would be no need to measure more than one of these traits. Accurate pedigree information is the basis for genetic evaluation, and further investigation targeting its improvement is recommended.

\section{Literature Cited}

Alenda, R., T. G. Martin, J. F. Lasley, and M. R. Ellersieck. 1980. Estimation of genetic and maternal effects in crossbred cattle of Angus, Charolais and Hereford parentage. II. Postweaning growth, ribeye area and fat cover. J. Anim. Sci. 50:235-241.

Arnold, J. W., J. K. Bertrand, L. L. Benyshek, and C. Ludwig. 1991. Estimates of genetic parameters for live animal ultrasound, actual carcass data, and growth traits in beef cattle. J. Anim. Sci. 69:985-992.

Boldman, K. G., L. A. Kriese, L. D. Van Vleck, C. P. Van Tassell, and S. D. Kachman. 1995. A manual for use of MTDFREML. A set of programs to obtain estimates of variances and covariances. ARS, USDA, Washington, DC.

Choi, S. B., J. W. Lee, N. S. Kim, S. H. Na, J. F. Keown, and L. D. Van Vleck. 2000. Estimation of genetic parameters for direct, maternal, and grandmaternal genetic effects for birth, weaning, and six month weights of Hanwoo (Korean Native Cattle). AsianAus. J. Anim. Sci. 2000. Vol. 13, No. 2:149-154.

Diop, M. 1997. Design and analysis of open nucleus breeding systems for cattle in Senegal. Ph.D. thesis. Univ. of Nebraska-Lincoln, Lincoln.

Dodenhoff, J., L. D. Van Vleck, and D. E. Wilson. 1999. Comparison of models to estimate genetic effects for weaning weight of Angus cattle. J. Anim. Sci. 77:3176-3184.

Graser, H.-U., S. P. Smith, and B. Tier. 1987. A derivative-free approach for estimating variance components in animal models by restricted maximum likelihood. J. Anim. Sci. 64:1362-1370.

Kersey DeNise, R. S., and D. E. Ray. 1987. Postweaning weights and gains of cattle raised under range and gain test environments. J. Anim. Sci. 64:969-976.

Koch, R. M. 1978. Selection in beef cattle. III. Correlated response of carcass traits to selection for weaning weight, yearling weight and muscling score in cattle. J. Anim. Sci. 47:142-150.

Koch, R. M., L. V. Cundiff, K. E. Gregory, and G. E. Dickerson. 1973. Genetic and phenotypic relations associated with preweaning and postweaning growth of Hereford bulls and heifers. J. Anim. Sci. 36:235-239.

Koots, K. R., J. P. Gibson, and J. W. Wilton. 1994. Analyses of published genetic parameter estimates for beef production traits. 2. Phenotypic and genetic correlations. Anim. Breed. Abst. 62:825-853.

Lee, C., and E. J. Pollak. 1997. Relationship between sire $\times$ year interactions and direct-maternal genetic correlation for weaning weight of Simmental cattle. J. Anim. Sci. 75:68-75.

Lee, D. H., B. K. Ohh, Y. I. Park, O. Y. Shin, and Y. H. Yang. 1991. Estimation of genetic parameters for economic traits in Korean Native Cattle. II. Heritabilities and genetic correlations for growth traits by Henderson's method 3. Korean J. of Anim. Sci. 33:520-524.

Mackinnon, M. J., K. Meyer, and D. J. S. Hetzel. 1991. Genetic variation and covariation for growth, parasite resistance and heat tolerance in tropical cattle. Livest. Prod. Sci. 27:105-122.

Meyer, K. 1992. Variance components due to direct and maternal effects for growth traits of Australian beef cattle. Livest. Prod. Sci. 31:179-204.

Robinson, D. L. 1994. Models which might explain negative correlations between direct and maternal genetic effects. In: Proc. 5th World Congr. Genet. Appl. Livest. Prod. 18:378-380.

Smith, S. P., and H.-U. Graser. 1986. Estimating variance components in a class of mixed models by restricted maximum likelihood. J. Dairy Sci. 69:1156-1165. 